\title{
Generic Digital Equity Model in Education: Mobile-Assisted Personalized Learning (MAPL) through e-Modules
}

\author{
Sheng Jia Song $(\mathbb{D}$, Kim Hua Tan *(1) and Mohd Mahzan Awang * $(\mathbb{D}$ \\ Faculty of Education, Universiti Kebangsaan Malaysia, Bangi 43600, Malaysia; shengjia.9324@gmail.com \\ * Correspondence: kimmy@ukm.edu.my (K.H.T.); mahzan@ukm.edu.my (M.M.A.); Tel.: +60-1-9273-5440
}

Citation: Song, S.J.; Tan, K.H.; Awang, M.M. Generic Digital Equity Model in Education: Mobile-Assisted Personalized Learning (MAPL) through e-Modules. Sustainability 2021, 13, 11115. https://doi.org/ $10.3390 /$ su131911115

Academic Editors:

Carlos Hervás-Gómez, María

Dolores Díaz-Noguera,

Pedro Román-Graván and María de los Ángeles Domínguez-González

Received: 16 September 2021

Accepted: 5 October 2021

Published: 8 October 2021

Publisher's Note: MDPI stays neutral with regard to jurisdictional claims in published maps and institutional affiliations.

Copyright: (C) 2021 by the authors. Licensee MDPI, Basel, Switzerland. This article is an open access article distributed under the terms and conditions of the Creative Commons Attribution (CC BY) license (https:/ / creativecommons.org/licenses/by/ $4.0 /)$.

\begin{abstract}
This study addresses the challenges most learners face in Third World and developing countries concerning education accessibility in an emergency. On the basis of the shortcomings found in a review of past studies, this scoping review introduces adapted model mobile-assisted personalized learning (MAPL), which focused on full distance learning using the personalized learning (PL) concept. This concept is rarely used in the classrooms of Third World and developing countries. MAPL is technology-integrated and customized PL but it does not depend on artificial intelligence. This model bridges the digital divide that hinders learners in accessing education by providing flexibility, regardless of weak internet reception or low bandwidth, among other hindrances, in Third World or developing countries. Learners in these countries inevitably opt for mobile devices as their preferred learning tool. MAPL is necessary and can aid underprivileged learners who are highly dependent on mobile devices. Rethinking and reforming current teaching practices are required. In this study, a pool of 60 articles from 2011 to 2021 was qualitatively synthesized. Among the articles, 29 focused on PL, 15 on mobile learning, and 16 on the potentials of MAPL. The findings indicate that MAPL could be a viable solution for achieving equity in education for every learner during full-fledged distance learning.
\end{abstract}

Keywords: digital equity; mobile learning; personalized learning; Education 4.0

\section{Introduction}

The unprecedented COVID-19 pandemic has led to the abrupt closure of schools in many countries. With the "new normal", the learning mode for learners has transitioned from physical learning to virtual learning. Whether digitally literate or not, teachers have had to adopt and adapt to new teaching circumstances via a virtual and distant environment, the result of which has been a drastic increase in the use of the Internet and electronic equipment. In some countries, the transition may be the first experience people have had of conducting school lessons entirely online. Traditional classrooms no longer fit into this "new normal". However, looking on the bright side, it could be a positive transition. Hanover [1] and Izmeztiev [2] oppose the idea of physical classroom learning because of the unfriendly and stiff nature of traditional instructional approaches. They assert that learners become demotivated, which leads to their unsatisfactory academic performance. Furthermore, traditional educational systems tend to provide a "one-size-fitsall" instructional model and cannot adjust to the different backgrounds, abilities, or interests of learners. Thus, if a thoughtful learner-centered instructional method is considered, the mode shift to online learning may be a blessing in disguise. In this regard, Reyna [3] has found online learner-centered approaches effective in shifting the learning experiences of medical students and promoting their self-discipline during the pandemic.

Nevertheless, traditional classroom learning has undeniably irreplaceable benefits, as addressed by Tran [4]. Face-to-face interaction among learners and teachers, which allows discussion and feedback in many ways, is unlikely to happen in an online classroom setting. Active participation, and the interest of students in learning certain lesson content, 
can be promptly distinguished and managed by teachers when face-to-face interaction is constant. Halupa [5] points out that online learning focuses more on digital rather than interpersonal relationships. Furthermore, the overuse of technology can have drawbacks to the physical, mental, emotional, and social development of learners. Therefore, both approaches have their pros and cons. The shift to online learning will be more effective when the prevention measures for its disadvantages are addressed.

Thus, digital equity is necessary to balance out the disadvantages. The International Baccalaureate Organization [6] states that all learners in an online classroom can equally learn when they have access to suitable personal learning devices, sufficient Internet bandwidth, time-zone-friendly classes, helpful feedback from teachers or classmates, varied learning experiences, and meaningful screen time. By equipping them with equal learning opportunities, learners can be encouraged to effectively participate. Therefore, these methods can amplify the positive impact of online learning. Although the actions of various developing countries can be witnessed through The World Bank Group [7] analysis, some underlying problems can be detected for learners in developing countries who are not granted the chance to learn online equally [8-10]. Therefore, devising a teaching approach is needed to make this undesirable situation more promising.

Considering the new approach, and the fact that learners would be unprepared for it, Blagg et al. [8], Hamid and Khalidi [9], and Lakulu et al. [10] expressed their concern for the abrupt implementation of distance learning during the pandemic. They expressed fear of the potential incompetency, on the part of learners and parents, in the face of an unrecognizable learning environment. Unprivileged learners face a variety of issues, such as low socioeconomic status, linguistic isolation, single parents, insufficient distance learning devices, poor Internet access, weakly distributed and unorganized information through smartphones, a lack of TV channels broadcasting educational programs, and crowded households. Most of those who live in remote areas cannot attend online classes because of low bandwidth or limited Internet access. Learners may gradually show less interest and engagement in online learning as the difficulties in participating in online learning increase.

Hamid and Khalidi [9] explain that a country's development level has an influence on the country's e-learning adoption level. In some countries with higher incomes, online learning is more feasible and is at a developing stage, whereas countries with lower incomes inevitably opt for learning through radio and television. In Industrial Revolution 4.0, the "Digital Evolution", prevailing digital technologies have gradually assumed more significant roles in education. As cited in Hussin [11], Fisk pinpointed the nine core trends related to Education 4.0. During the pandemic, some of these trends have gained more in significance. They are as follows: (1) Learning occurs flexibly in any location or any time. (2) Personalized learning (PL) can take place, and learners can have more authority to decide how they learn. (3) The ideas of learners are considered in the designing and updating of the curriculum. (4) Learners are prone to become independent learners in Education 4.0. (5) The assessment methods for learners may differ from conventional evaluation platforms. The pandemic quickened the need for developing countries to explore an Education-4.0aligned learning approach for students. Furthermore, such an approach has initiated the cause for allowing impoverished learners equal online learning opportunities.

The World Bank Group [7] listed the educational and technological mediums used across 66 developing countries to support distance learning during the COVID-19 pandemic. The main alternative employed by 42 countries was educational television programs, followed by radio in 24 countries. Television was the main device used to support learning in rural areas in developing countries, which have limited or no Internet access. Some examples of these countries are Argentina, Croatia, Mexico, South Sudan, and Turkey. Meanwhile, countries such as Colombia, Guyana, and Jamaica have printed learning materials for underprivileged learners. Some other minor alternatives that do not involve cellular network connections are memory cards, CDs, and prerecorded videos for offline viewing. Educational lessons accessible through mobile phones are facilitated through so- 
cial media platforms (e.g., Facebook and YouTube), web service platforms (i.e., WhatsApp, Skype, and Zoom), SMS, and online learning platforms (e.g., Google Classroom, Google Suite, Office 365, and the digital library).

Among the Asian countries, Japan conducted full ICT-based distance learning. In China, besides television broadcasting, mobile learning and massive open online courses were used as alternatives to teaching. Meanwhile, Cambodia is highly dependent on social media and mobile phones for online learning. India and Indonesia focused on offline and online approaches through television broadcasting and online learning platforms [7]. In Malaysia, the Ministry of Education (MOE) offered educational TV programs that collaborated with TV Okey RTM and the Astro broadcasting companies. DidikTV KPM and Slot TV Pendidikan were also established to air from $2-15 \mathrm{~h}$ of educational programs each day. Furthermore, a device pilot project known as the CERDIK initiative aimed to provide 150,000 free laptops and Internet service units to assist the underprivileged bottom $40 \%$ (B40). However, the number of units was still insufficient because approximately 333,000 learners did not own a suitable device for online education, according to a survey done by the MOE [9].

Therefore, most developing countries still face obstacles in providing equal education for learners. Despite the concerted efforts made by developing countries to assist incapable learners, some learners still cannot achieve the various forms of effective and maximal learning experiences because of the lack of suitable devices and Internet access. Some families share one laptop, which may make it difficult for learners to learn conveniently. Thus, teachers should consider utilizing the mobile device as a learning and teaching tool because it is more affordable. Thus, this study seeks to achieve an equal online education opportunity in developing countries for learners who use mobile devices as learning tools. In conjunction with the core ideas of Education 4.0, this study introduces an appropriate PL approach utilizing mobile devices to ensure an effective and engaging online learning experience for learners.

\section{Methodology}

\subsection{Study Review Design}

This study employed the scoping review as the study methodology. It was based on the six-stage methodological framework outlined by Arksey and O'Malley [12], with consideration given to the scoping framework suggested by Levac et al. [13]. The procedure is given in Figure 1. The scoping review is a method of research synthesis in which the literature of specific topics or research areas are connected to distinguish significant concepts, knowledge gaps, research agendas, decision-making inferences, evidence types, and sources to acknowledge the practice, policymaking, and research involved $[14,15]$.

According to Tricco et al. [16], a scoping review presents a broad overview of the literature evidence about a topic, regardless of the study quality. It is beneficial for scholars who want to study a newly introduced topic. In short, the scoping review reveals a process for generating hypotheses. In this study, the scoping review fits the purpose of discovering a newly adapted teaching and learning model: mobile-assisted personalized learning (MAPL) through e-modules to provide marginalized learners equal and quality distance learning opportunities. Given that this model has yet to be extensively reviewed, the scoping review's exploratory nature enables flexibility when adopting, analyzing, and reviewing any appropriate literature resourced on the focused topic or research area. Subsequently, the evidence collected can be mapped to reveal the potential of the proposed approach. 


\section{Stage 1 - Identifying the Research Questions}

- Consider the rationale and clarify the purpose.

- Articulate research questions clearly.

- Ensure the purpose is congruent with the research questions.

\section{Stage 2 - Identifying Relevant Studies}

- Scope of search is guided by the research questions.

- Search for resources in electronic databases, reference lists, hand-searching of key journals, existing networks, and relevant organisations.

- Decisions to limit the scope of need justification.

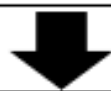

\section{Stage 3 - Study Selection}

- Eliminate studies based on inclusion / exclusion criteria.

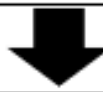

\section{Stage 4 - Charting the data}

- Synthesize and interpret qualitative aspects of data according to themes, decisions made about what information should be gleaned from the included studies.

\section{Stage 5 - Collating, Summarizing and Reporting the Results}

- This stage is a 3-step process:

(1) Numeric summary and qualitative thematic analysis are applied.

(2) Results and study outcomes reflect the purpose and the research questions.

(3) Meaning of findings is considered in relation to the purpose (research, practice, policy).

\begin{tabular}{|c|}
\hline Stage $6-$ Seeking Consultation (Optional) \\
\hline - Stakeholder consultation regarding potential studies to be included. \\
\hline
\end{tabular}

Figure 1. Six-stage methodological framework for scoping review, adapted from Arksey and O'Malley [9], and Levac, Colquhoun, and O'Brien [13].

In contrast to the scoping review, the systematic review examines questions specifically based on the selected criteria and tests the hypotheses, which is not practical for a newly developed idea [16]. Therefore, the scoping review methodology was chosen to distinguish all papers relevant to MAPL, regardless of their perceived strength, quality, and study design. The present study, as a result, may impart deep insight and exploration into how PL can take place with mobile technology, and yields a strong foundation for the digital equity of learners in online education. 


\subsection{Scoping Review Research Questions}

Setting up research questions is significant for the analysis of the selected topics. The alternatives for solving these questions are described in Figure 2 in order to elucidate the core concerns of the study, which are as follows:
a. What are the PL key elements and results?
b. What are the mobile learning key elements and results?
c. How can MAPL achieve digital equity?
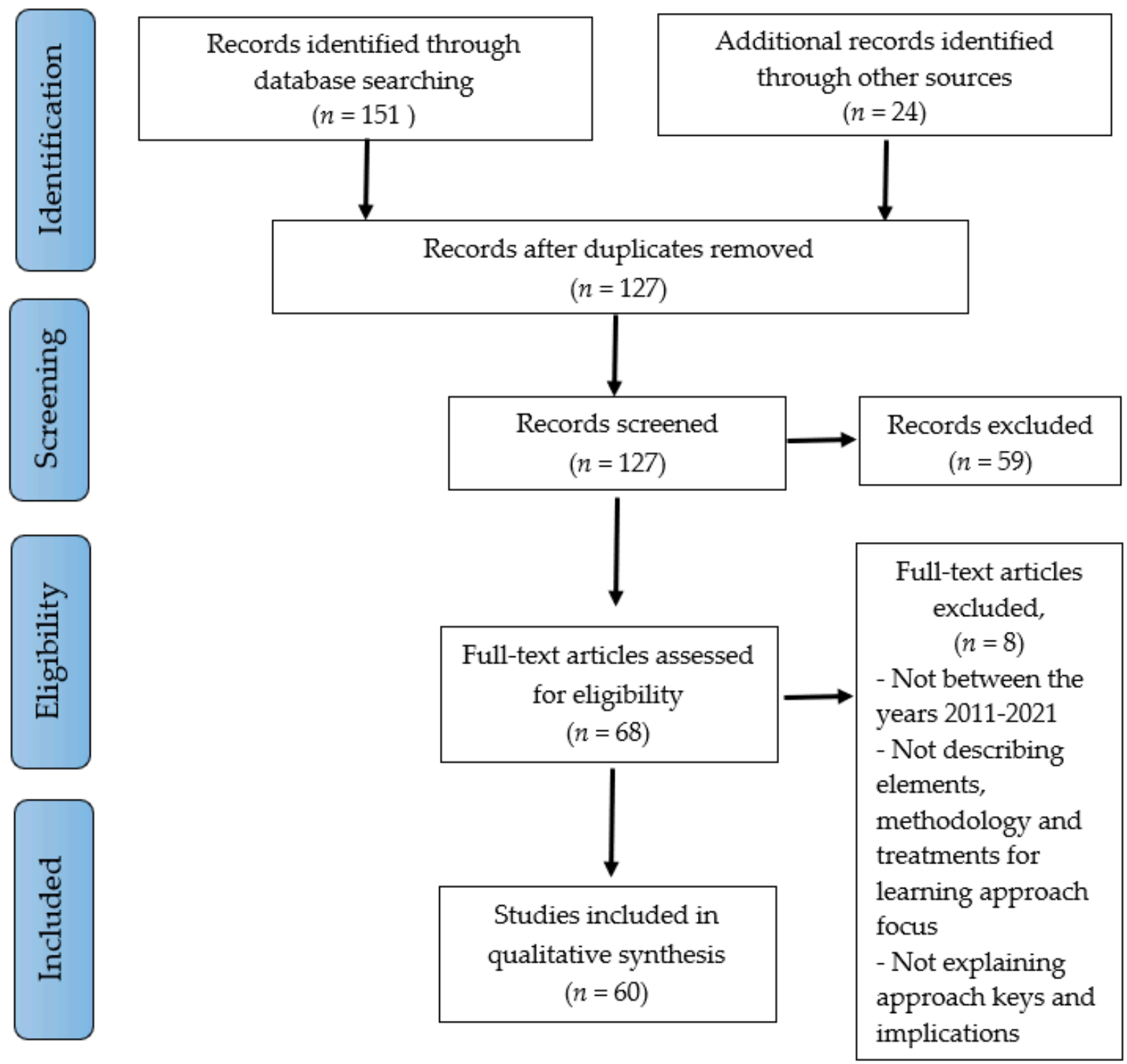

Figure 2. PRISMA flow diagram of study selection process. Source: Moher, Liberati, Tetzlaff, Altman, and The PRISMA Group [17].

The initial guiding questions are listed in Questions (a) and (b). Question (a) aims to investigate the key elements and past studies on personalized and mobile learning. A series of literature that utilized mobile learning and PL was scrutinized in order to answer Question (c). Finally, the study proposes a suitable approach to operationalize MAPL for achieving digital equity. A quality and fair online learning opportunity is yet to be widely introduced among learners in developing countries. This study attempts to reveal a flexible, cost-saving, and Internet-saving learning approach to realizing the engagement of students in distance learning. 


\subsection{Study Selection: Inclusion and Exclusion Criteria}

According to Peters et al. [18], evidence screening has two levels. First, on the basis of the titles and abstracts, the collected articles were screened to ensure their relevance to the main topic of the study. A total of 59 records were excluded, as displayed in Figure 2. Second, the whole texts for 68 articles were assessed for their eligibility. The inclusion criteria included articles that were published between 2011 and 2021. Other inclusion criteria included relevant organizational reports and findings, theoretical articles, such as literature reviews and recommendations based on cited research, and empirical articles, such as authentic qualitative or quantitative studies. The exclusion criteria were that the screening articles did not directly or indirectly relate to the elements, treatments, and methodologies contributing to MAPL. In sum, an article was removed from the literature review list if the following exclusion criteria were met: (1) The article was not published between 2011 and 2021; (2) The article did not describe personalized mobile learning elements, methodologies, or treatments; and (3) The article did not provide relevant key information, future recommendations, or approach implications. Out of 127 articles found, 60 were included in the analysis.

\subsection{Data Sources and Search Strategy}

From 127 sources, 60 articles on personalized and mobile learning were carefully chosen. These articles were used to identify keys, strategies, and solutions for reducing the digital divide in education through a viable distance learning model. Keyword searches were conducted on relevant electronic databases, such as Google Scholar, ResearchGate, and Springer Open. Other sources retrieved online were reference lists and hand-searched key journals, such as The Journal of Research on Technology in Education, which provided deep insight into MAPL. The selection of articles focused on the latest ones between 2011 and 2015. The search terms used for this review included "PL + mobile learning", and "PL + mobile-assisted learning".

\section{Findings and Discussion}

A total of 60 articles were finally retrieved from electronic databases and reference lists, and by hand-searching key journals. These papers discussed the key elements, various instruments, methodologies, and strategies for implementing MAPL. They were published in various countries from 2011-2021. Figure 3 portrays the publication trend.

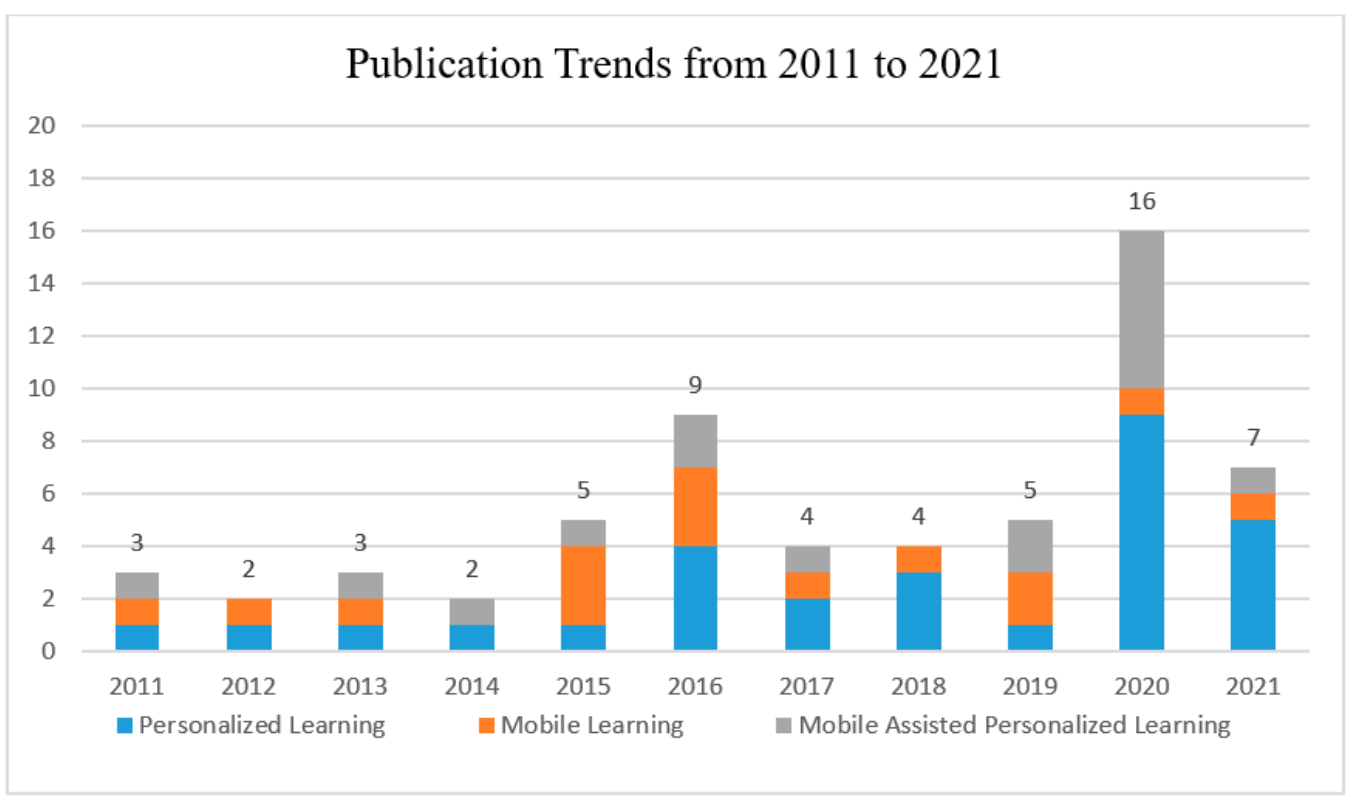

Figure 3. Publication trends from 2011 to 2021. 


\section{1. $P L$}

The concept of PL made its first prominent appearance in the early 20th century when philosophers of education, John Dewey, William Kilpatrick, and others, advocated learnercentered learning $[19,20]$. Dewey's philosophy guided educators to consider the interests, needs, and passions of learners in curriculum planning, and granted the learners choice and voice during the learning process [21,22]. As the years passed, different PL methods have been sought that consider the diversity of learners. In 1968, Fred Keller constructed a well-known learner-centered instructional model, known as the personalized instruction system. Acting as one of the PL forerunners, this mastery-oriented model allowed learners to learn independently at their own pace [23]. Even though the PL concept has long been known in education, it has only recently evolved into many forms, and learners can benefit from PL the most from online learning [24].

In contrast to curriculum-centered PL, the 21st-century PL is learner-centered and provides constructivist teaching practices and instructional strategies that allow for the individualization and differentiation of learners. It is a specific learning model that utilizes technology to customize instructions, and that pays attention to learners with different ability levels, needs, and interests [25-28]. From the perspectives of Hanover Research [1], the modern PL has some additional features to the above-mentioned characteristics. First, it emphasizes 21st-century teaching and learning skills. Learners can direct "how, what, when, and where" they learn, and it is connected with utilizing progressive technology. Furthermore, technology provides educators with the flexibility to adapt to learners' needs quickly and provide real-time access to customized content and resources [24]. In other words, learners take ownership of their learning.

For instance, technology-integrated PL can be conducted through adaptive learning, blended learning, cognitive analytics, cognitive learning systems, cognitive tutors, competency-based education, digital playlists, educational data mining, intelligent tutoring systems, learning analytics, learning management systems, learning progressions, and personalized learning plans $[19,25]$. In China, the Squirrel AI online learning system adopts adaptive learning technology to widely support the PL of K-12 school learners [29].

To prevent confusion, Hanover Research [1] clarified differences in personalization, individualization, and differentiation instructions, as shown below in Figure 4. In short, personalization is a mix of individualization and differentiation.

According to Abd Halim et al. [30], the rise of e-learning is insufficient for a conducive online learning environment because it still lacks personalization. Thus, the personalized learning environment (PLE) concept became infamous for its composed, organized, and packaged learning content. Teachers no longer control learners' learning. Hanover Research [1] stresses that an environment or culture that supports PL should be cultivated to carry out a successful PLE. In an ideal PLE, learners will feel motivated and interested in engaging in learning [31]. Moreover, it is also conducive to self-directed learning; teachers and learners collaborate to plan meaningful learning activities. In the meantime, teachers scaffold students' learning based on their previous knowledge, interests, and skill levels in order to nurture a constructivist environment. Lastly, tools, such as reflection, seminars, and long-term projects would be utilized by teachers to increase the initiative, cognitive skills, reflective skills, and problem-solving skills of students in learning specific knowledge. Teachers should always view the PLE as a crucial element in conducting a PL lesson. 


\begin{tabular}{|c|c|c|}
\hline INDIVIDUALIZATION & DIFFERENTIATION & PERSONALIZATION \\
\hline $\begin{array}{l}\text {-The learning pace follows the } \\
\text { students' learning needs. } \\
\text { - Every student has the same } \\
\text { learning goal, but their speed } \\
\text { of going through material will } \\
\text { be adjusted according to their } \\
\text { learning needs. } \\
\text { - Longer time can be given to } \\
\text { students to learn assigned } \\
\text { topics. They can choose to } \\
\text { skip already known topics or } \\
\text { information and repeat a } \\
\text { topic. }\end{array}$ & $\begin{array}{l}\text { - Instruction follows the } \\
\text { students' learning } \\
\text { preferences. } \\
\text { - Every student has the same } \\
\text { learning goal, but the way the } \\
\text { student receives instruction is } \\
\text { changed based on each } \\
\text { student's preferences or is } \\
\text { adapted from research best } \\
\text { found instruction that suits the } \\
\text { students. }\end{array}$ & $\begin{array}{l}\text { - Instruction follows the } \\
\text { pace of students' learning } \\
\text { needs, their learning } \\
\text { preferences, and specific } \\
\text { interests. } \\
\text { - The learning objectives, } \\
\text { content, method and pace } \\
\text { differ for each student. } \\
\text { - Inclusive of } \\
\text { differentiation and } \\
\text { individualization criteria. }\end{array}$ \\
\hline
\end{tabular}

Figure 4. Individualization, differentiation and personalization. Source: U.S. Department of Education (2012) in Hanover Research [1].

For a successful PL implementation, Johns and Wolking [32] recommend four elements. The first element is a flexible content tool that encourages differentiated paths, paces, and performance tasks. It is highly customizable and has integrated digital content instruction. It lets learners know the reason for utilizing the selected digital tool. The second element is targeted instruction. Personalized instruction should be in sync with the needs and learning goals of learners. Furthermore, flexibility in grouping learners according to their needs is needed to convey targeted instruction. The third element is the reflection and ownership of learners, where learners are given the opportunities to make ongoing reflection, promoting the ownership of their own learning [33]. Lastly, a successful PL should have data-driven decisions. The data collected often influence the instructions and grouping. Benson in Patrick, Kennedy, and Powell [27] proposed four necessary elements for a PL model: learner profiles (skills, gaps, strengths, weaknesses, interests, and aspirations); personal learning paths (goals and objectives); individual mastery (continuous assessment according to performed mastery); and a flexible learning environment. In order to extract and combine the indicated elements of a well-prepared PL lesson, learners would have their profiles set up or initially ready. During a PL lesson, from the data collected by teachers, learners are individually given instructions, as well as flexible content and tools, and they learn via a flexible environment. In each lesson, learners are aware of their learning paths and can reflect on them from time to time. Finally, they will be assessed according to their learning paths at the end of each lesson. This cycle repeats for the next goals and objectives [27].

Successful PL can improve one's metacognitive, social, and emotional competencies [34]. DeMink-Carthew et al. [35] stress the significance of PL in strengthening the social and emotional learning and self-awareness of learners in terms of acknowledgment, metacognition, and reflection on their weaknesses, strengths, and behaviors. Learners should be given the right to make meaningful decisions, support and reflect on their strengths, connect their feelings with learning experiences, and obtain the results. Furthermore, Gerasimova and Schevlyagin [36] support earlier claims that the following social and emotional skills (SES) can be promoted: perseverance and grit, emotional regulation, selfefficacy, collaboration, metacognition, and self-regulation. Furthermore, Alamri et al. [37] 
proved PL effectiveness in providing learners with self-determination and intrinsic motivation in online higher education.

Olofson et al. [38] reported a broad implementation of PL in American middle schools. A survey was performed on 232 middle-grade teachers who were involved in PL. By 2017, the teachers started utilizing PL in a class or a large group of learners, personalized assessment, out-of-school learning, as well as the technology context. Walkington and Bernacki [39] provide insight into PL implementation in various academic subjects in a physical classroom setting. Despite the different forms of PL being taken, they argue that an ideal PL practice has PL practitioners who: (1) are clear about the PL approach and theory that are aligned to the characteristics of learners and their learning environment; (2) maintain researcher-teacher-leader connections for design-based PL research; (3) frequently gather observational data for the effectiveness of PL approaches; and (4) conduct research on boosting the control, choice, and ownership of learners during PL.

Targeting the K-12 high and low academic performance learners in the United States, Lee et al. [40] studied how teachers dealt with both categories of learners differently. While conducting PL in a classroom with high-performing learners, the teachers tend to conduct more detailed and technology-based PL. They consider the career goals of learners while planning PL, share project learning outcomes, evaluate nonacademic outcomes, and forge a deep relationship with more learners. Despite the implementation differences, PL practice and technology integration benefited the academic performance of learners [40-43]. Focusing on K-12 learners, Tsybulsky [44] tested the impacts of digital curation and the utilization of digital tools in choosing, preserving, collecting, arranging, classifying, and sharing digital assets on a PL science subject through a phenomenological qualitative approach. The outcome indicates the potential for digital curation in PL and the improvement of cognitive and emotional learning experiences.

In an American high school, teacher-created modules were used to implement blended PL lessons [25]. These modules shared learning content and allowed teachers to extract data in order to detect weak learners and categorize learners based on their ability. Furthermore, assessment could also be done from time to time to provide prompt feedback and carry out mastery-based grading practices. Following PL criteria, these modules contained personalized objectives, content, activities, and assessments. Learners were fully informed of their learning progress throughout the learning event. Illuminate or Canvas applications were used by the teacher to discipline and monitor learners.

Alamri et al. [45] conducted an integrative literature review in higher education and identified three technology models that supported PL: digital badges, adaptive learning technology, and competency-based technology. Digital badges use a learner dashboard as the main feature, whereas the latter two adopted algorithm-based tutoring systems. They were proven advantageous when used in traditional learning environments, and effective in increasing the learning engagement of students.

Given the outbreak of COVID-19, Major and Francis [46] performed a rapid evidence review on the application of technology-supported PL in low- and middle-income countries (LMICs) to relieve mass school shutdown complications. Technology-supported PL showed great potential when applied among school-age learners during the current pandemic in LMICs. Although learners kept on learning outside classrooms and schools, the features of PL could still ensure positive learning outcomes and were believed to decrease the educational gaps for marginalized learners.

The literature has shown that PL can produce better academic performances from learners because of its nature in meeting the learning needs and interests of every learner. Learner-centered learning has become a demanding trend in Education 4.0. Furthermore, PL efficacy in fostering SES is undeniably essential and should not be neglected. It is also perceived as a tool to achieve educational equity [36]. Most importantly, it can reveal significant differences among the school learners of LMICs. Despite these features, testing of the integration of the teacher-created module strategy into a fully online format is necessary. Nevertheless, it may be suitable for teachers in developing countries to start 
their PL practice because they are familiar with creating modules. The key elements of PL found in earlier studies can significantly contribute to PL teaching ideas. The extra abilities teachers need to acquire for distance learning will be the skills necessary to teach online and their understanding of PL. Instead of depending on the learning platform that charges learners, zero-rated or low-cost learner-friendly alternatives and digital resources can be sought out to maximize the PL experience of learners. This is aligned with the idea of providing a quality education in which the needs and interests of every underprivileged learner can be met, regardless of the circumstances. Figure 6 summarizes the key concepts of PL.

\begin{tabular}{|c|c|}
\hline Study & Key Concepts of PL \\
\hline$[19,20]$ & - Learner-centered learning since early 20th century \\
\hline$[21,22]$ & - Learners own freedom to choose and voice. \\
\hline [23] & - Learners learn independently at own pace. \\
\hline [24] & $\begin{array}{l}\text { - PL evolved into many forms for online learning. } \\
\text { - Technology enables flexibility to adapt to learners' needs, allow quick and real-time } \\
\text { access to customized content and resources. }\end{array}$ \\
\hline$[19,25]$ & - Types of technology integrated PL \\
\hline$[25-28]$ & $\begin{array}{l}\text { - } 21^{\text {st }} \text { century PL allows individualization and differentiation. } \\
\text { - Utilizes technology to customize instructions based on learners' ability, levels, needs, } \\
\text { and interests. }\end{array}$ \\
\hline [1] & $\begin{array}{l}\text { - Additional features of modern PL: } \\
\text { i) Emphasized 21:t century teaching and learning skills } \\
\text { ii) Learners are aware of "how, what, when, and where" they can learn } \\
\text { iii) Connected with utilizing progressed technology } \\
\text { - Differences in personalization, individualization, and differentiation }\end{array}$ \\
\hline [19] & - Suggested infrastructure to support learner-centered learning \\
\hline [29] & - AI online learning system/ adaptive learning technology for school learners \\
\hline$[19,33]$ & - Gain ownership of learning \\
\hline$[30]$ & - Significance of personalization in e-learning [Personalized Learning Environment (PLE)] \\
\hline$[1,31]$ & - PLE increases learners' learning motivation and engagement. \\
\hline [1] & $\begin{array}{l}\text { - Criteria of PLE: } \\
\text { i) Conducive for self-directed learning. } \\
\text { ii) Teachers and learners collaborate to plan meaningful learning activities } \\
\text { iii) Learners' learnings are scaffolded } \\
\text { iv) Encourage learners' initiatives, cognitive skills, reflective skills, and problem-solving } \\
\text { skills through tools }\end{array}$ \\
\hline [32] & $\begin{array}{l}\text { - Four crucial PL implementation elements: } \\
\text { i) Flexible content tool } \\
\text { ii) Targeted instruction } \\
\text { iii) Learners' reflection and ownership } \\
\text { iv) Data driven decisions }\end{array}$ \\
\hline [27] & $\begin{array}{l}\text { - Four significant elements in a PL model } \\
\text { i) Learner profiles } \\
\text { ii) Personal learning paths } \\
\text { iii) Individual mastery } \\
\text { iv) Flexible learning environment }\end{array}$ \\
\hline [34] & - Boosts metacognitive, social, and emotional competencies. \\
\hline [35] & - Strengthens social and emotional learning (SEL) \\
\hline [36] & $\begin{array}{l}\text { - Improves social and emotional skills (SES) } \\
\text { - A tool to achieve educational equity. }\end{array}$ \\
\hline [37] & - Gains self-determination and intrinsic motivation. \\
\hline [38] & - Wide PL implementation in American middle schools. \\
\hline [39] & $\begin{array}{l}\text { - PL in physical classroom setting } \\
\text { - Criteria of PL practitioners: } \\
\text { i) Knowledgeable in PL approach and theory } \\
\text { ii) Maintain researcher-teacher-leader connections for PL research }\end{array}$ \\
\hline
\end{tabular}

Figure 5. Key concepts of PL. 


\begin{tabular}{|c|c|}
\hline & $\begin{array}{l}\text { iii) Frequent collection of PL approaches effectiveness data } \\
\text { iv) Study on gaining learners' freedom of choice and voice }\end{array}$ \\
\hline [40] & $\begin{array}{l}\text { - Effective classroom with high-performing learners: } \\
\text { i) More detailed and technology-based PL } \\
\text { ii) consider learners' career goal } \\
\text { iii) evaluate non-academic outcomes } \\
\text { iv) Strong relationship with more learners }\end{array}$ \\
\hline [40-43] & - Technology integrated PL boosts learners' academic performance. \\
\hline [44] & $\begin{array}{l}\text { - Digital curation supplements PL. } \\
\text { - Better cognitive and emotional learning experiences. }\end{array}$ \\
\hline [25] & $\begin{array}{l}\text { - Teacher-created modules for blended PL lessons: } \\
\text { - Shared learning content } \\
\text { ii) Categorize learners based on ability } \\
\text { iii) Contain personalized objectives, content, activities and assessments. } \\
\text { iv) Learners are informed of learning progress }\end{array}$ \\
\hline [45] & $\begin{array}{l}\text { - Models that support personalized learning: } \\
\text { i) Digital badges } \\
\text { ii) Adaptive learning technology } \\
\text { iii) Competency-based technology }\end{array}$ \\
\hline [46] & $\begin{array}{l}\text { - Technology-supported personalized learning in the times of low- and middle-income } \\
\text { countries (LMICs) school shutdown ensures positive learning outcome and reduce } \\
\text { educational gaps for marginalized learners. }\end{array}$ \\
\hline
\end{tabular}

Figure 6. Key concepts of PL.

\subsection{Mobile Learning}

Concerning technology-mediated learning theory [47], mobile learning, also known as "M-Learning", is defined as the online, distance, or modern learning method using portable or wireless computing devices, such as handheld and tablet computers, MP3 players, smartphones, and mobile phones [6,48-51]. The invention of various program applications and social networking sites or software has meant that $\mathrm{m}$-learning has undergone considerable leaps of advancement [50].

In Malaysia, Ariffin [52] conducted a qualitative study among local university learners to inspect their learning on self-generated mobile learning activities and found that they had a better understanding of the subjects they studied online. Masrom et al. [53], and Abdul Latef et al. [54], also discovered positive attitudes and a readiness toward m-learning among Malaysian teachers, lecturers, and learners.

M-learning for language, known as mobile-assisted language learning (MALL), is a strategy widely used in foreign language education and has lasted at least a decade [55]. Cakmak [55] cited Chen and Hsu's stand on the potential of MALL in producing positive language learning outcomes. According to his findings, the previous MALL research has been based on two approaches. First, content-based MALL studies concentrate on designing language learning materials and activities. Second, the design and learner need to improve the participation and motivation of learners in learning L2. These studies have proven the effectiveness of MALL in L2 learning. Concerning Education 4.0, Bonfield et al. [56] discovered notable positive changes in mobile learning courses among UK and international higher education providers by providing bite-sized modules that can be accessed whenever and wherever the learners wanted. For successful mobile learning, Baker et al. [57] stress that the lessons carried out should be purposeful, meaningful, and effective.

Nevertheless, Balaji et al. [48], and Qoussini et al. [58], highlight some of the potential disadvantages of mobile learning, such as: the limited screen size, short battery life, insufficient memory capacity, difficulty in printing, inconvenient use of moving graphics, and more distractions. Cakmak [55] states the need to reflect on the limited screen size problem and improve oral communication and collaboration among learners. Despite the above-mentioned m-learning challenges, some of these limitations can be mitigated or prevented with rapid technological advancements. Teachers should first examine the 
advantages and disadvantages of their teaching methods and see if they suit the features and characteristics of mobile-based learning in order to overcome other existing problems.

The International Baccalaureate Organization [6] has designed a 4C framework to indicate the decent implementation of mobile learning. Moreover, it could broaden the experiences of learners who do not own laptops at home or lack convenient access to high bandwidth. The 4Cs are as follows:

(i) Content: learning is supported with media, such as documents, audio, or video.

(ii) Computer: data are collected from the learner and are processed.

(iii) Capture: data are collected from sensors (camera and GPS) and are saved for sharing or reflection.

(iv) Communicate: learners are interconnected.

This framework can be advantageous in assisting underprivileged learners in developing countries with distance learning.

With the advent of mobile phones, a huge potential was created for a more progressive educational paradigm. A significant amount of earlier literature has proven the success of mobile technologies in reaching learners and providing them with more possibilities in terms of learning forms, tools, and resources. Mehdipour and Zerehkafi [49] expressed an increasing need for m-learning in developing countries for mobility, accessibility, and affordability. Furthermore, Bachore [59] reports portability and connectivity as the two main advantages of mobile devices. Thus, the mobile device is a suitable alternative for underprivileged learners for online learning at equitable levels. The digital gap can be reduced when more online learning opportunities are available. Figure 7 sums up the key concepts of mobile learning.

\begin{tabular}{|c|l|}
\hline Study & \multicolumn{1}{c|}{ Key Concepts of Mobile Learning } \\
\hline$[47]$ & $\bullet$ Technology-mediated learning theory \\
\hline$[6,48-51]$ & $\begin{array}{l}\text { • online, distance or modern learning method using portable or wireless computing } \\
\text { devices }\end{array}$ \\
\hline$[50]$ & $\bullet$ Appearance of program applications and social networking sites \\
\hline$[52]$ & - Self-generated mobile learning activities promotes subjects understanding. \\
\hline$[53,54]$ & $\begin{array}{l}\text { - Optimistic attitude and readiness of teachers, lecturers, and learners towards m- } \\
\text { learning. }\end{array}$ \\
\hline$[55]$ & $\begin{array}{l}\text { - Introduction of Mobile Assisted Language Learning (MALL) } \\
\text { - MALL promotes positive language learning outcome. } \\
\text { - Two common approaches of MALL: }\end{array}$ \\
\hline$[56]$ & $\begin{array}{l}\text { i) Content-based } \\
\text { ii) Design and learner need } \\
\text { - Needs alternatives to improve oral communication and collaboration among } \\
\text { learners. }\end{array}$ \\
\hline$[57]$ & Flexible access of bite-size modules improves m-learning. \\
\hline$[48,58]$ & $\bullet$ Potential demerits of mobile learning \\
\hline$[6]$ & $\begin{array}{l}\text { - 4C framework for well-implemented mobile learning: } \\
\text { i) Content } \\
\text { ii) Computer } \\
\text { iii) Capture } \\
\text { iv) Communicate }\end{array}$ \\
\hline$[49]$ & $\begin{array}{l}\text { - Mobility, accessibility, and affordability increases needs for m-learning in } \\
\text { developing countries. }\end{array}$ \\
\hline$[59]$ & $\begin{array}{l}\text { Two core advantages of mobile devices: } \\
\text { i) Portability } \\
\text { ii) Connectivity }\end{array}$ \\
\hline
\end{tabular}

Figure 7. Key concepts of mobile learning. 


\subsection{Potentials of $M A P L$}

Mobile learning has amplified the possibilities of personalization in learning. Cisco [60] asserts that a personalized environment and context must be prepared, and learners should be asked some questions in order to achieve personalization through mobile learning. Next, learners give personalized responses using their mobile devices anytime and anywhere. These features may be videos, audio, texts, collaborations, and other modes available. Given the various features available, mobile learning can suit different learning needs and styles, such as those required by visual, auditory, reading/writing, and kinesthetic learners. In addition to accommodating diverse learners, mobile learning is especially helpful in getting learners involved and offers access to expertise and collaboration [60]. However, the employment of mobile technologies in PL should ensure that they are highly portable, individual, unobtrusive, available, adaptable, persistent, useful, and user-friendly [49].

According to Mehdipour and Zerehkafi [46], and Radhakrishnan [61], m-learning has many benefits that make it a suitable option for PL. These advantages are: relatively inexpensive opportunities; multimedia content delivery and creation options; continuous and situated learning support; improved literacy levels, numeracy, and participation in education; and the communication features of mobile phones as part of a larger learning activity. Particularly, m-learning can eliminate communication barriers between learners and their teachers. M-learning works effectively with learner-centered learning. In a sense, it supports distance learning and PL $[48,60,62,63]$. Furthermore, learners can feel positive about the PL system in mobile learning [64]. Thus, m-learning has potential for PL.

Ally and Tsinakos [65] point out that many learners skip the personal computer stage and head straight to learning via mobile devices. As a result, learning materials that are accessible through mobile devices are in high demand. Qoussini et al. [58] support the use of mobile learning for its capacity to let learners engage in authentic world learning and gain motivation, and learn confidence and autonomy, unrestricted by time and location. Mobile learning is viable individually or collaboratively and it encourages social communications. Most significantly, it is suitable for PL because of its flexibility as learner-centered content and it serves as a tool for assessments and surveys. Reinforcing earlier comments, Traxler [66] states that PL could be achieved successfully when learners focus on their personal goals and have autonomy in selecting media. Whalley et al. [67] assert that mobile devices are ideal in nurturing PLEs that pay attention to the learning needs of learners. Educational quality can be enhanced because of the omnipresence and flexibility of PLEs. Given the status of the COVID-19 pandemic, it is more feasible to venture into decent mobile learning.

While conducting PL, Internet access and digital devices are the required basics $[1,68]$. Given that the focus of this study is on the use of mobile devices, some essential points need consideration for distance learning. First, the device's screen size should be big enough to show websites and applications in order to boost participation. Another point is that if learners encounter limited network access, they should be given an option for accessing and downloading the learning content anytime and anywhere. This feature is vital because downloadable content provides the flexibility for learners to resume their learning, regardless of the restrictions faced at a particular time [1].

To conduct mobile learning aligned with the PL concept, Toh et al. [51] introduced the idea of knowledge personalization. Generally, knowledge personalization means that the knowledge offered to learners should be based on their characteristics, abilities, and behaviors. At times, learning through mobile technology may lead to learners undergoing learning individually because of the lack of constant supervision and guidance from teachers. Therefore, learners have to learn ways to monitor and manage their own knowledge-gaining processes [43]. As a result, knowledge personalization in PL is indispensable for providing learners with diverse learning abilities and behaviors with different ways to manage their knowledge. Figure 8 shows the framework of knowledge personalization [51]. It is divided into three categories: context, content, and learner. Similarly, Hashim and Ahmad [69] also developed a mobile school conceptual framework that comprised 
three main components: learner, device, and social aspects. These should be the focus aspects of teachers when planning knowledge input for learners.

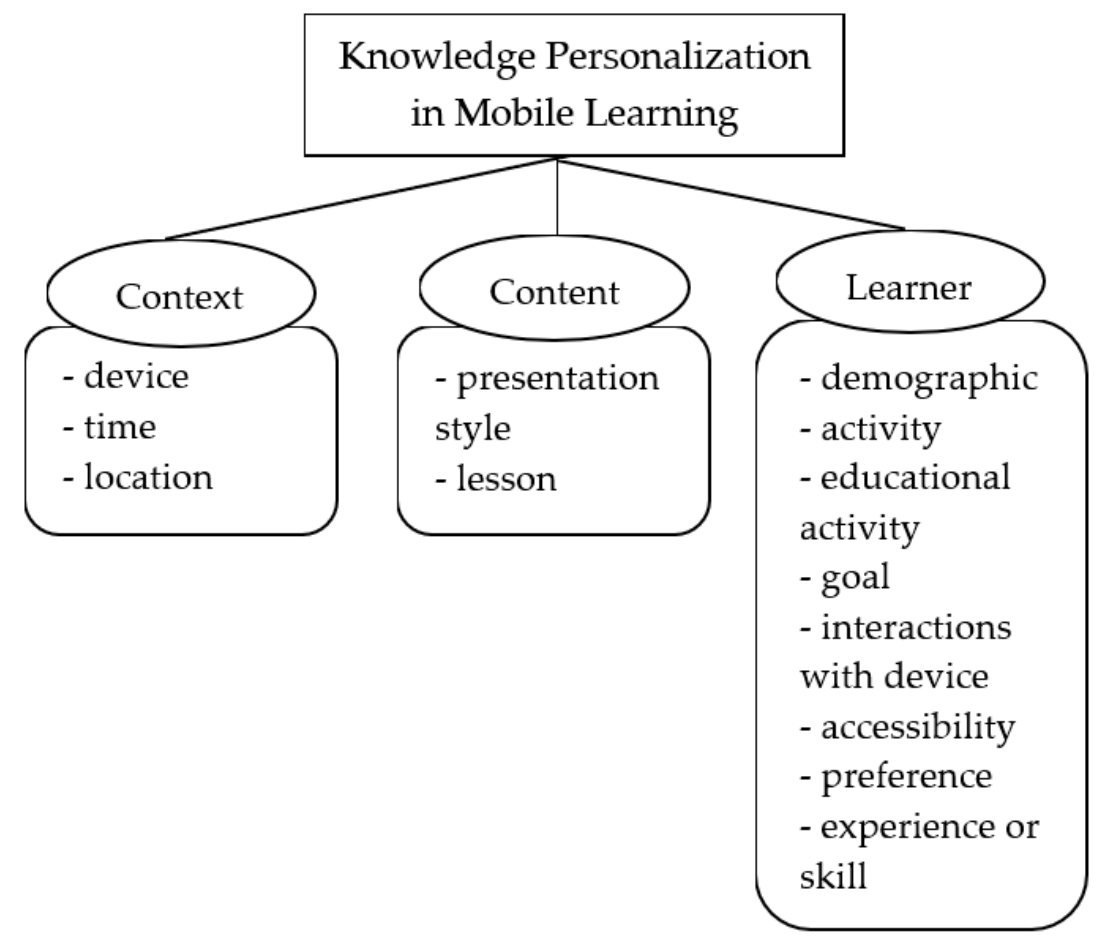

Figure 8. Framework of knowledge personalization.

Al-Razgan and Alotaibi [70], and Zhang et al. [31], held an intervention with a personalized Android app and observed the prominent positive attitudes of language learners toward personalized mobile learning systems. Similarly, a comparative study was conducted by Zou et al. [71] on assisting the personalized vocabulary learning of EFL learners through task recommendation in e-learning systems. They found a close relationship between English vocabulary improvement and online PL. Chen and Hsu (as cited in Cakmak [55]) also consolidated the foundation of personalized MALL in producing positive language learning outcomes. Finally, Kukulska-Hulme [72] deeply explored the personalization of language learning through mobile technologies and reiterated that PL was applicable for individual and group learning. Such learning gives people social experiences. Generally speaking, MAPL in distance learning has much potential. In terms of the academic performance and engagement level, PL and MALL show promising signs. The integration of these strategies may create a great distance learning opportunity for learners, especially those who cannot enjoy the benefits of all of the online learning features. PL is flexible enough for teachers to plan learning content and tools according to the situations and needs of learners.

As the literature reveals, the gaps indicate that most studies related to m-learning have focused more on higher education, perhaps because m-learning is not a learning strategy that is in high demand in primary or secondary schools. These school lessons usually take place in a physical classroom setting in developing countries. The idea of a fully m-learning-implemented and PL-implemented environment is still fresh among primary and secondary school learners. According to a review study by Xie et al. [73], research on personalized or adaptive learning through portable devices is yet to be explored. Thus, researchers should commence research in this field to benefit more learners whose families own mobile devices only. Furthermore, studies on PL implementation with regard to language are limited. More research should be carried out in order to reveal the effects of PL in MALL. Moreover, when the scope is narrowed down, only a short amount of relevant PL research has been conducted in developing countries. Therefore, developing countries 
need more breakthroughs to keep up with the ideology of Education 4.0. These countries should acknowledge the existence of the digital divide between urban and rural school learners in order to improve the condition. A well-planned MAPL is needed to compensate for the shortcomings among disadvantaged learners. Figure 9 illustrates the potential of MAPL as a whole.

\begin{tabular}{|c|c|}
\hline Study & Potential of Mobile Assisted Personalized Learning \\
\hline [60] & $\begin{array}{l}\text { - Ways to achieve personalization through mobile learning: } \\
\text { i) Ready personalized environment and context } \\
\text { ii) Prompts learners' feedback } \\
\text { iii) Learners could give personalized responses anytime and anywhere } \\
\text { - Benefits: } \\
\text { i) Caters to different learning needs and styles } \\
\text { ii) Gains learners' participation } \\
\text { iii) Provides access to expertise and collaboration }\end{array}$ \\
\hline [49] & $\begin{array}{l}\text { - Crucial criteria of mobile technologies in PL: } \\
\text { i) Highly portable } \\
\text { ii) Individual } \\
\text { iii) Unobtrusive, } \\
\text { iv) Available } \\
\text { v) Adaptable } \\
\text { vi) Persistent } \\
\text { vii) Useful } \\
\text { viii) User-friendly }\end{array}$ \\
\hline$[46,61]$ & $\begin{array}{l}\text { - Advantages of m-learning that suits PL: } \\
\text { i) Affordable } \\
\text { ii) Multimedia content delivery and creation options } \\
\text { iii) Continuous and situated learning support } \\
\text { iv) Improved levels of literacy, numeracy, and participation in education } \\
\text { v) The communication features of a mobile phone as part of a larger learning activity }\end{array}$ \\
\hline$[48,60,62,63]$ & - M-learning supports distance learning and PL. \\
\hline [64] & - Learners' positive attitude towards PL system in mobile learning. \\
\hline [65] & - High demand for mobile devices learning materials. \\
\hline [58] & $\begin{array}{l}\text { - Rationale of m-learning for PL: } \\
\text { i) Promotes authentic world learning } \\
\text { ii) Gain motivation } \\
\text { iii) Improves learning confidence } \\
\text { iv) Increases autonomy } \\
\text { v) Not restricted by time and location. }\end{array}$ \\
\hline [66] & - Personal goals and autonomy in selecting media complement PL. \\
\hline [67] & - Mobile devices are ideal in nurturing PLE. \\
\hline$[1,68]$ & $\begin{array}{l}\text { - Basics in PL using mobile devices: } \\
\text { i) Internet access } \\
\text { ii) Digital devices }\end{array}$ \\
\hline [1] & $\begin{array}{l}\text { - Consideration for distance learning: } \\
\text { i) Screen size of device } \\
\text { ii) Learning content can be accessed and downloaded anytime and anywhere }\end{array}$ \\
\hline [51] & Introduction to framework of knowledge personalization \\
\hline [43] & Importance of learners monitoring own knowledge-gaining process. \\
\hline [69] & Introduction to mobile school conceptual framework. \\
\hline$[31,70]$ & Positive attitudes of language learners towards personalized mobile learning systems. \\
\hline [71] & Language learning improvement through online personalized learning. \\
\hline [55] & Positive language learning outcomes through personalized MALL. \\
\hline [72] & $\begin{array}{l}\text { Personalization of language learning through mobile technologies are doable for both } \\
\text { individual and group learning. }\end{array}$ \\
\hline [73] & $\begin{array}{l}\text { Research on personalized or adaptive learning through portable devices needs further } \\
\text { exploration. }\end{array}$ \\
\hline
\end{tabular}

Figure 9. Potential of MAPL. 


\subsection{Achieving Digital Equity: MAPL through E-Modules}

With the emergence of new teaching approaches, some findings and suggestions from the studies were adopted and adapted to provide a proper and suitable generic digital equity model for underprivileged learners, namely, MAPL through E-Modules, as shown in Figure 10.

\section{Step 1- Create learner profiles}

- Identify learners' individual learning needs, skills, gaps, proficiency level, strengths, weaknesses, preferred learning styles, interests, or aspirations (based on teacher's lesson focus).

\section{Step 2- Create personal learning paths for learning lesson}

i) Assign learning goals and objectives based on each learner's needs and proficiency

- $\quad x$ Introduce a PL concept to learners.

- $*$ Develop a flexible method to group learners.

- Allow learners to create their own unique way of demonstrating mastery (choose and set goal) on a particular concept or objective (powerful way to develop learner ownership).

- $*$ Gain engagement: Facilitate a discussion on a specific topic with each small group. (Eg: Any suitable mobile social networking platform)

- Individual remediation: Provide one-on-one tutoring for learners who have not mastered the concept.

- Progress tracking: Prepare a "data wall" to identify learner needs and reinforce the importance of using data.

ii) Giving task via e-modules

- Task content: Refers school textbooks and curriculum choices.

- Optimize available m-learning resources: Flexible instructional approaches, content or tools (accommodate learners' circumstances, challenges).

- Build downloadable content and learning experiences in a modular format. (Learners can learn at different pace or time.)

- E-modules follow framework of knowledge personalisation. (Refer to Figure 5)

- Assign duration: Differentiate the path, pace, or performance task of learning.

\section{Step 3 - Continuous assessment of individual mastery / mastery-based grading}

i) Provide constructive feedback

- Assess and provide feedback to learners' modules answers. (Learners send via any suitable mobile social networking platform.)

- State each learner's achievement level (bronze, silver, or gold) based on modules' assessments results.

- $\quad$ **omote collaboration: Allows peer feedback.

ii) Upon Each Completion of Module

- Create modules ahead of time to let learners move through the levels at their own pace. (Each mastery has clear learning standard and objectives.)

- Collect, analyse, and use learner data. (Can have different method of collecting and collaborate with teachers if possible.)

- $\quad$ Frequent informal and formal measurement.

\section{Step 4 - Leamer reflection}

i) Learners reflect on their progress, learning and goals through any possible way. For examples:

- $*$ Journal Entry

- $\quad$ Learner E-Portfolio (Develop portfolios of work with learners)

Figure 10. Steps to mobile-assisted personalized learning (MAPL) through e-modules. ** Optional, according to the needs or preferences of teachers. 
The sources of inspiration and ideas in creating MAPL lessons through e-modules are as given below:

(i) Johns \& Wolking [32]: Four elements

(ii) Bingham [25]: Personalization through teacher-created modules

(iii) Toh et al. [51]: Framework of knowledge personalization in mobile learning

(iv) Patrick et al. [27]; McCarthy et al. [42]: Essential components of PL

(v) Glowa \& Goodell (2016), as cited in Groff [19]: Suggest infrastructures to support learner-centered learning.

A flow chart with a detailed step-by-step explanation guides teachers in smoothly carrying out MAPL through the e-modules. The usage of e-modules adapts the idea of bitesized learning that has been proven effective in enhancing m-learning [56]. Meanwhile, the online downloadable learning content of the e-modules allows convenient access anytime and anywhere.

To gain ideas for various instructional approaches, Zayabalaradjane [74] recommends a few suitable behavioral indicators with respective activity examples to determine the online learning engagement of learners:

(i) Observational learning behaviors: read emails and discussion posts, watch videos, refer to notes and documents, and maintain constant virtual attendance;

(ii) Application learning behaviors: share thoughts on forums, reply to emails, answer online quizzes or tests, share questions, post requests or provide feedback, make clarifications, share own created resources, and make progress in learning.

As a matter of fact, the learners who face complications tend to lose focus and the motivation for engaging in online learning easily. An effective way to increase the participation of learners is to provide appreciation and incentives for their achievement. Some helpful incentives include grades, certificates, rewards, gamified badges, guidance, and self-assessment rubrics. These guidelines can be convenient when teachers wish to motivate the learners and show more appreciation for them while applying the MAPL approach. Moreover, planning pedagogical tools in various forms via social media or online learning platforms is another way to keep learners motivated [75].

The integration of multimodal digital technologies in MAPL lessons, as above, can also effectively engage learning in online classroom settings. As the technology advances over time, the needs of multiliteracies in distance learning classrooms has been increasing [76]. Moreover, fun learning experiences should also be created to decrease the stress of distance learners adapting to emergent learning [77]. In this case, applying gamification features on teaching tools can bring forth the desired expectation [78]. In a study conducted by Azmi et al. [79], the usage of data-driven learning (DDL) in Kibbitzers language modules again proved MAPL that encouraged data-driven decisions in order to be more beneficial for self-paced and self-accessed learning.

Reviewing the past studies, this generic digital equity model, MAPL through EModules, which has applied the concept of PL and m-learning, is promising because of its capability in achieving digital equity. M-learning provides a strong foundation because of its affordability, mobility, and flexibility. It is compatible with the PL that focuses on every learner's needs and interests. Hence, a quality and equal education is realizable with the application of MAPL through e-modules.

\section{Conclusions}

This study adopted the scoping review as a literature review method. The 60 studies on MAPL reveal some research gaps: (1) the introduction of MAPL in developing countries; (2) the full online primary/secondary school implementation of MAPL; (3) the application of MAPL in language subjects; and (4) the ways to achieve education equality in developing countries through MAPL. Research on bridging these gaps would be helpful for uncovering the potentials of MAPL as a progressive and guiding teaching and learning model. With the world-scale COVID-19 outbreak, these findings may help to overcome the 
challenges schools face in developing countries in providing quality and equal education to underprivileged learners who do not own a computer or laptop to engage in distance learning. The flexibility of e-modules can efficiently allow learners to access full distance learning across time and space. While learning through mobile devices makes equal distance learning chances more realizable, PL that focuses specifically on the individual needs and interests of learners can ensure equity in education. The four gaps emphasized above may be addressed by researchers in future studies for proper answers. As technology progresses every day, distance learning becomes even more relevant. Everyone should always be prepared to face any possible or unexpected school closures, taking the repercussions of this pandemic as a lesson. Therefore, an exploration of the best distance learning strategies should be a continuous process in order to continue to bring enlightenment to this large-scale education evolution, inspired by Education 4.0.

Author Contributions: Conceptualization, S.J.S.; Methodology, S.J.S. and K.H.T.; Writing-original draft preparation, S.J.S. and K.H.T.; Writing—review and editing, K.H.T. and M.M.A.; Visualization, S.J.S.; Supervision, K.H.T.; Project Administration, S.J.S.; Funding Acquisition, M.M.A.; Validation, K.H.T. All authors have read and agreed to the published version of the manuscript.

Funding: This research was supported by Faculty of Education, Universiti Kebangsaan Malaysia (PP-FPEND-2021).

Institutional Review Board Statement: Not applicable.

Informed Consent Statement: Informed consent was obtained from all subjects involved in this study.

Data Availability Statement: Not applicable.

Conflicts of Interest: The authors declare no conflict of interest.

\section{References}

1. Hanover Research. Best Practices in Personalized Learning Implementation. Available online: https:/ /www.hanoverresearch. $\mathrm{com} /$ media/Best-Practices-in-Personalized-Learning-Implementation.pdf (accessed on 25 April 2021).

2. Izmestiev, D. Personalized Learning: A New ICT-Enabled Education Approach; UNESCO Institute for Information Technologies in Education: Moscow, Russia, 2012.

3. Reyna, J. Twelve tips for COVID-19 friendly learning design in medical education. MedEdPublish 2020, 9, 103. [CrossRef]

4. Tran, B. Educational experiences with traditional, online and hybrid learning environments. Educ. J. 2016, 3, 60-63.

5. Halupa, C. Risks: The impact of online learning and technology on learner physical, mental, emotional, and social health. In Proceedings of the 9th Annual International Conference of Education, Research and Innovation (ICERI2016), Seville, Spain, 14-16 November 2016; pp. 6305-6314. [CrossRef]

6. International Baccalaureate Organization. Online Learning, Teaching and Education Continuity Planning for Schools. Available online: https: / / www.ibo.org/globalassets/news-assets / coronavirus/online-learning-continuity-planning-en.pdf (accessed on 25 April 2021).

7. The World Bank Group. How Countries Are Using Edtech (Including Online Learning, Radio, Television, Texting) to Support Access to Remote Learning during the COVID-19 Pandemic. Available online: https://www.worldbank.org/en/topic/edutech/ brief/how-countries-are-using-edtech-to-support-remote-learning-during-the-covid-19-pandemic (accessed on 25 April 2021).

8. Blagg, K.; Blom, E.; Gallagher, M.; Rainer, M. Mapping Learner Needs during COVID-19; Support Urban Institute: Washington, DC, USA, 2020

9. Hawati, A.H.; Khalidi, J.R. Covid-19 and Unequal Learning; Khazanah Research Institute: Kuala Lumpur, Malaysia, 2020.

10. Lakulu, M.M.; Othman, M.Z.; Panessai, I.Y.; Amat, M.R. The framework of mobile e-learning based on embedded technology for rural schools. Int. J. Acad. Res. Bus. Soc. Sci. 2019, 9, 735-743. [CrossRef]

11. Hussin, A.A. Education 4.0 made simple: Ideas for teaching. Int. J. Educ. Lit. Stud. 2018, 6, 92-98. [CrossRef]

12. Arksey, H.; O'Malley, L. Scoping studies: Towards a methodological framework. Int. J. Soc. Res. Methodol. 2005, 8, 19-32. [CrossRef]

13. Levac, D.; Colquhoun, H.; O’Brien, K.K. Scoping studies: Advancing the methodology. Implement. Sci. 2010, 5, 1-9. [CrossRef]

14. Daudt, H.M.; van Mossel, C.; Scott, S.J. Enhancing the scoping study methodology: A large, inter-professional team's experience with Arksey and O'Malley's framework. BMC Med. Res. Methodol. 2013, 13, 48. [CrossRef]

15. Pham, M.; Rajić, A.; Greig, J.; Sargeant, J.; Papadopoulos, A.; Mcewen, S. A scoping review of scoping reviews: Advancing the approach and enhancing the consistency. Res. Synth. Methods 2014, 5, 371-385. [CrossRef]

16. Tricco, A.; Lillie, E.; Zarin, W.; O’Brien, K.; Colquhoun, H.; Kastner, M.; Levac, D.; Ng, C.; Sharpe, J.; Wilson, K.; et al. A scoping review on the conduct and reporting of scoping reviews. BMC Med. Res. Methodol. 2016, 16, 15. [CrossRef] 
17. Moher, D.; Liberati, A.; Tetzlaff, J.; Altman, D.G.; The PRISMA Group. Preferred reporting items for systematic reviews and meta-analyses: The PRISMA statement. PLoS Med. 2009, 6, e1000097. [CrossRef]

18. Peters, M.D.; Marnie, C.; Tricco, A.C.; Pollock, D.; Munn, Z.; Alexander, L.; McInerney, P.; Godfrey, C.M.; Khalil, H. Updated methodological guidance for the conduct of scoping reviews. JBI Evid. Synth. 2020, 18, 2119-2126. [CrossRef]

19. Groff, J.S. Personalized learning: The state of the field \& future directions. Center for Curriculum Redesign. 2017, 47. Available online: https://dam-prod.media.mit.edu/x/2017/04/26/PersonalizedLearning_CCR_April2017.pdf (accessed on 25 April 2021).

20. Redding, S. Competencies and personalized learning. In Handbook on Personalized Learning for States, Districts, and Schools; Murphy, M., Redding, S., Twyman, J.S., Eds.; Center on Innovations in Learning, Temple University: Philadelphia, PA, USA, 2016; pp. 3-18.

21. Basham, J.D.; Hall, T.E.; Carter, R.A., Jr.; Stahl, W.M. An operationalized understanding of personalized learning. J. Spec. Educ. Technol. 2016, 31, 126-136. [CrossRef]

22. Tienken, C.H. Unstandardized and personalized. Kappa Delta Pi Rec. 2018, 54, 106-108. [CrossRef]

23. Allen, C.O. Personalized System of Instruction and Learner Performance in High School Weight Training Courses. Doctoral Thesis, Liberty University, Lynchburg, VA, USA, 2015. Available online: https://digitalcommons.liberty.edu/cgi/viewcontent. cgi? article $=2096 \&$ context $=$ doctoral (accessed on 25 April 2021).

24. Zhou, L.; Zhang, F.; Zhang, S.; Xu, M. Study on the personalized learning model of learner-learning resource matching. Int. J. Inf. Educ. Technol. 2021, 11, 143-147.

25. Bingham, A.J. A look at personalized learning: Lessons learned. Kappa Delta Pi Rec. 2019, 55, 124-129. [CrossRef]

26. Easley, M. Personalized learning environments and effective school library programs. Knowl. Quest 2017, 45, 16-23.

27. Patrick, S.; Kennedy, K.; Powell, A. Mean What You Say: Defining and Integrating Personalized, Blended and Competency Education; International Association for K-12 Online Learning: Vienna, VA, USA, 2013.

28. Shemshack, A.; Spector, J.M. A systematic literature review of personalized learning terms. Smart Learn. Environ. 2020, 7, 33. [CrossRef]

29. Huang, R.H.; Liu, D.J.; Tlili, A.; Yang, J.F.; Wang, H.H. Handbook on Facilitating Flexible Learning during Educational Disruption: The Chinese Experience in Maintaining Undisrupted Learning in COVID-19 Outbreak; Smart Learning Institute of Beijing Normal University: Beijing, China, 2020.

30. Abd Halim, N.D.; Ali, M.B.; Yahaya, N. Personalized learning environment: Accommodating individual differences in online learning. In Proceedings of the International Conference on Social Science and Humanity (ICSSH 2011), Singapore, 26-28 February 2011.

31. Zhang, L.; Basham, J.D.; Yang, S. Understanding the implementation of personalized learning: A research synthesis. Educ. Res. Rev. 2020, 31, 100339. [CrossRef]

32. Johns, S.; Wolking, M. The Core Four of Personalized Learning: The Elements You Need to Succeed; Education Elements: San Carlos, CA, USA, 2016.

33. Cheung, S.K.; Wang, F.L.; Kwok, L.F.; Poulova, P. In search of the good practices of personalized learning. Interact. Learn. Environ. 2021, 29, 179-181. [CrossRef]

34. Murphy, M.; Redding, S.; Twyman, J. Handbook on Personalized Learning for States, Districts, and Schools; IAP: Charlotte, NC, USA, 2016.

35. DeMink-Carthew, J.; Netcoh, S.; Farber, K. Exploring the potential for learners to develop self-awareness through personalized learning. J. Educ. Res. 2020, 113, 165-176. [CrossRef]

36. Gerasimova, I.; Schevlyagin, M. How personalized learning platforms could improve social-emotional skills. In Proceedings of the 15th International Technology, Education and Development Conference (INTED 2021), Valencia, Spain, 8-9 March 2021.

37. Alamri, H.; Lowell, V.; Watson, W.; Watson, S.L. Using personalized learning as an instructional approach to motivate learners in online higher education: Learner self-determination and intrinsic motivation. J. Res. Technol. Educ. 2020, 52, 322-352. [CrossRef]

38. Olofson, M.W.; Downes, J.M.; Smith, C.P.; LeGeros, L.; Bishop, P.A. An instrument to measure teacher practices to support personalized learning in the middle grades. RMLE Online 2018, 41, 1-21. [CrossRef]

39. Walkington, C.; Bernacki, M.L. Appraising research on personalized learning: Definitions, theoretical alignment, advancements, and future directions. J. Res. Technol. Educ. 2020, 52, 235-252. [CrossRef]

40. Lee, D.; Huh, Y.; Lin, C.; Reigeluth, C.; Lee, E. Differences in personalized learning practice and technology use in high- and low-performing learner-centered schools in the United States. Educ. Technol. Res. Dev. 2021, 69, 1221-1245. [CrossRef]

41. McCarthy, E.M.; Liu, Y.; Schauer, K.L. Strengthsbased blended personalized learning: An impact study using virtual comparison group. J. Res. Technol. Educ. 2020, 52, 353-370. [CrossRef]

42. McCarthy, K.S.; Watanabe, M.; Dai, J.; McNamara, D.S. Personalized learning in iSTART: Past modifications and future design. J. Res. Technol. Educ. 2020, 52, 301-321. [CrossRef]

43. Huang, R.H.; Liu, D.J.; Zhan, T.; Amelina, N.; Yang, J.F.; Zhuang, R.X.; Chang, T.W.; Cheng, W. Guidance on Active Learning at Home during Educational Disruption: Promoting Learner's Self-Regulation Skills during COVID-19 Outbreak; Smart Learning Institute of Beijing Normal University: Beijing, China, 2020.

44. Tsybulsky, D. Digital curation for promoting personalized learning: A study of secondary-school science learners' learning experiences. J. Res. Technol. Educ. 2020, 52, 429-440. [CrossRef] 
45. Alamri, H.A.; Watson, S.; Watson, W. Learning technology models that support personalization within blended learning environments in higher education. TechTrends 2021, 65, 62-78. [CrossRef]

46. Major, L.; Francis, G.A. Technology-Supported Personalized Learning: Rapid Evidence Review; EdTechHub: Bolton, UK, 2020. [CrossRef]

47. Bower, M. Technology-mediated learning theory. Br. J. Educ. Technol. 2019, 50, 1035-1048. [CrossRef]

48. Balaji, R.D.; Al-Mahri, F.; Malathi, R. A perspective study on content management in e-learning and m-learning. arXiv 2016, arXiv:1605.02093.

49. Mehdipour, Y.; Zerehkafi, H. Mobile learning for education: Benefits and challenges. Int. J. Comput. Eng. Res. $2013,3,93-101$.

50. Park, Y. A pedagogical framework for mobile learning: Categorizing educational applications of mobile technologies into four types. Int. Rev. Res. Open Distrib. Learn. 2011, 12, 78-102. [CrossRef]

51. Toh, S.Y.; Abdullah, N.S.; Miskon, S.; Rahman, A.A.; Habil, H. A framework of knowledge personalization in mobile learning. J. Theor. Appl. Inf. Technol. 2016, 89, 122-132.

52. Ariffin, S.A. Mobile learning learner-generated activities from learners' perspectives: Malaysian context. In Mobile Learning in Higher Education in the Asia-Pacific Region; Springer: Singapore, 2017; pp. 315-339.

53. Masrom, M.; Nadzari, A.S.; Mahmood, N.H.N.; Zakaria, W.N.W.; Ali, N.R.M. Mobile learning in Malaysia education institutions. Issues Inf. Syst. 2016, 17, 152-157.

54. Abdul Latef, A.S.; Frohlich, D.; Calic, J.; Muhammad, N.H. Teachers' perceptions towards implementing mobile learning in rural Malaysia. In Proceedings of the 1st International MEDLIT Conference, Kuala Lumpur, Malaysia, 5-6 March 2018; UMK Press: Kuala Lumpur, Malaysia, 2018; pp. 267-284.

55. Cakmak, F. Mobile learning and mobile assisted language learning in focus. Lang. Technol. 2019, 1, 30-48.

56. Bonfield, C.A.; Salter, M.; Longmuir, A.; Benson, M.; Adachi, C. Transformation or evolution?: Education 4.0, teaching and learning in the digital age. High. Educ. Pedagog. 2020, 5, 223-246. [CrossRef]

57. Baker, A.; Dede, C.; Evans, J. The 8 Essentials for Mobile Learning Success in Education. Qualcomm Wireless Reach. Available online: https://www.qualcomm.com/media/documents/files/the-8-essentials-for-mobile-learning-success-in-education.pdf (accessed on 25 April 2021).

58. Qoussini, A.E.; Jusoh, Y.; Tabib, S. A review on personalization in mobile learning. Int. J. Comput. Sci. Issues 2015, 12, 17-26.

59. Bachore, M.M. Language learning through mobile technologies: An opportunity for language learners and teachers. J. Educ. Pract. 2015, 6, 50-53.

60. Cisco. The Mobile Learning Phenomenon in Education: Accelerating the Delivery of Personalized Learning. Redrock Reports. Available online: https://info.hbcommunications.com/hubfs/content/MobileLearning.pdf (accessed on 25 April 2021).

61. Radhakrishnan, M. Personalized mobile learning and course recommendation system. Int. J. Mob. Blended Learn. 2021, 13, 38-48. [CrossRef]

62. Brown, T.H.; Mbati, L.S. Mobile learning: Moving past the myths and embracing the opportunities. Int. Rev. Res. Open Distrib. Learn. 2015, 16, 115-135. [CrossRef]

63. Ziden, A.A.; Rosli, M.; Gunasegaran, T.; Azizan, S.N. Perceptions and experience in mobile learning via SMS. Int. J. Interact. Mob. Technol. 2017, 11, 116-132. [CrossRef]

64. Huang, H.C.; Wang, T.Y.; Hsieh, F.M. Constructing an adaptive mobile learning system for the support of personalized learning and device adaptation. Procedia-Soc. Behav. Sci. 2012, 64, 332-341. [CrossRef]

65. Ally, M.; Tsinakos, A. Increasing Access through Mobile Learning; Commonwealth of Learning: Vancouver, BC, Canada, 2014; ISBN 978-1-894975-64-3.

66. Traxler, J. Introduction. In Making Mobile Learning Work: Case Studies of Practice; Traxler, J., Wishart, J., Eds.; ESCalate and HEA Subject Centre for Education: Bristol, UK, 2011.

67. Whalley, B.; France, D.; Park, J.; Mauchline, A.; Welsh, K. Towards flexible personalized learning and the future educational system in the fourth industrial revolution in the wake of Covid-19. High. Educ. Pedagog. 2021, 6, 79-99. [CrossRef]

68. Bingham, A.J.; Pane, J.F.; Steiner, E.D.; Hamilton, L.S. Ahead of the curve: Implementation challenges in personalized learning school models. Educ. Policy 2018, 32, 454-489. [CrossRef]

69. Hashim, A.S.; Ahmad, W.F.W. Mobile school conceptual model for secondary schools in Malaysia. Jurnal Teknologi 2016, 78, 1-11. [CrossRef]

70. Al-Razgan, M.; Alotaibi, H. Personalized mobile learning system to enhance language learning outcomes. Indian J. Sci. Technol. 2019, 12, 1-9. [CrossRef]

71. Zou, D.; Wang, M.; Xie, H.; Cheng, G.; Wang, F.L.; Lee, L.K. A comparative study on linguistic theories for modeling EFL learners: Facilitating personalized vocabulary learning via task recommendations. Interact. Learn. Environ. 2020, 29, 270-282. [CrossRef]

72. Kukulska-Hulme, A. Personalization of Language Learning through Mobile Technologies. Cambridge University Press: Cambridge, UK, 2016.

73. Xie, H.; Chu, H.-C.; Hwang, G.-J.; Wang, C.-C. Trends and development in technology-enhanced adaptive/personalized learning: A systematic review of journal publications from 2007 to 2017. Comput. Educ. 2019, 140, 103599. [CrossRef]

74. Zayabalaradjane, Z. COVID-19: Strategies for online engagement of remote learners. F1000Research 2020, 9, 1-11.

75. Jong, B.; Tan, K.H. Using padlet as a technological tool for assessment of learners' writing skills in online classroom settings. J. Int. Educ. Pract. 2021, 9, 411-423. [CrossRef] 
76. Ang, L.H.; Tan, K.H. A review of theories and practices of multiliteracies in classroom: Issues and trends. Int. J. Learn. Teach. Educ. Res. 2020, 19, 41-52. [CrossRef]

77. Temban, M.M.; Tan, K.H.; Mohd Said, N.E. Exploring informal learning opportunities via YouTube Kids among children during COVID-19. Acad. J. Interdiscip. Stud. 2021, 10, 272. [CrossRef]

78. Idris, M.; Said, N.; Tan, K.H. Game-based learning platform and its effects on present tense mastery: Evidence from an ESL classroom. Int. J. Learn. Teach. Educ. Res. 2020, 19, 13-26. [CrossRef]

79. Aimi Azmi, N.; Kim Hua, T.; Ho Abdullah, I.; Azman, H. The efficacy of Kibbitzer in solving specific language problems among ESL Undergraduates. Int. J. Engl. Lang. Lit. Stud. 2021, 10, 83-93. 